\title{
Natural Gas Storage Seismic Monitoring
}

\author{
J.L. Mari ${ }^{1}$, F. Huguet ${ }^{2}$, J. Meunier ${ }^{3}$ and M. Becquey ${ }^{4}$ \\ 1 IFP Energies nouvelles, IFP School, 228-232 avenue Napoléon Bonaparte, 92852 Rueil-Malmaison Cedex - France \\ 2 GDF Suez/STORENGY, 361 avenue du Président Wilson, 93200 Saint-Denis - France \\ 3 CGGVeritas, 1 rue Léon Migaux, 91341 Massy - France \\ 4 IFP Energies nouvelles, 1-4 avenue de Bois-Préau, 92852 Rueil-Malmaison Cedex - France \\ e-mail: j-luc.mari@ifpen.fr - frederic.huguet@gdf-suez.com - julien.meunier@cggveritas.com - marc.becquey@ifpen.fr
}

Résumé - Suivi sismique des stockages de gaz naturel - IFP Energies nouvelles, la CGGVeritas et GDF Suez ont mené ensemble, depuis 1980, de nombreuses expériences de monitoring sismique afin de détecter et de suivre les mouvements du gaz dans des stockages géologiques de gaz naturel. Des acquisitions ont été réalisées à différents stades de la vie du stockage tant en sismique de surface qu'en sismique de puits. Des antennes de récepteurs permanentes ont été construites et implantées dans des puits. Des sources permanentes ont été conçues et utilisées de façon continue pendant plusieurs années pour suivre le cycle remplissage/extraction du stockage. Les dispositifs permanents ont permis d'améliorer la précision des mesures de temps d'arrivée jusqu'au dixième de milliseconde.

L'arrivée de gaz dans un aquifère se traduit par une rapide variation de vitesse, qui a un impact à la fois sur les temps d'arrivée des réflexions sous les réservoirs et sur les amplitudes aux limites du réservoir.

Les mouvements ultérieurs du contact gaz/eau avec le cycle de remplissage/soutirage sont plus difficiles à suivre et nécessitent une excellente précision des mesures de temps d'arrivée des réflexions. L'inversion de ces mesures pour l'estimation des saturations en gaz et en eau est délicate. Cette inversion a été tentée, avec un certain succès, dans le cas de Céré-la-Ronde.

Du fait de la densité du dioxyde de carbone, au-delà d'une profondeur de 800 mètres environ, cette inversion risque d'être encore plus délicate pour les stockages de $\mathrm{CO}_{2}$ que pour les stockages de gaz naturel.

\begin{abstract}
Natural Gas Storage Seismic Monitoring - IFP Energies nouvelles, CGGVeritas and GDF Suez have conducted together, since 1980, a series of seismic monitoring experiments in order to detect and follow the movements of the gas plume in natural gas geologic storages. Surface and well seismic surveys were carried out at different stages of the storage life. Permanent receiver arrays have been set down in wells. Permanent sources have been designed. Sources and receivers have been used to follow continuously the storage cycle during several years, providing time measurement accuracy within a tenth of a millisecond.

Gas intrusion into an aquifer leads to an increase in the arrival times of reflections beneath the storage reservoir and to a variation of the reflection amplitudes at top and bottom of the reservoirs.

Progressive variations of the seismic parameters may be followed during the initial infill period. Further movements of the gas plume with the annual in/out cycles are more difficult to follow, because of the simultaneous presence of gas and water in the pores. Arrival time variations of some tenths of a millisecond may be detected and measured. Saturations, using accurate picking of the arrival times, can be estimated in favourable cases.

Because of the higher density of carbon dioxide, when stored in a supercritical phase, sensitivity of the seismic parameters, velocity, density and acoustic impedance to saturation variations will be about twice smaller for $\mathrm{CO}_{2}$ storages than it is for methane.
\end{abstract}




\section{INTRODUCTION}

Natural gas underground storages were created for strategic purposes. They are also utilized to regulate the gas supply. Gas is stored from spring to autumn when the demand is lower and withdrawn from October to April, when cold weather increases heating needs.

Gaz de France (foundation member of present GDF Suez), $C G G$ (foundation member of present CGGVeritas) and IFP Energies nouvelles have developed and tested seismic monitoring methods to follow first how the gas was set down into the storage reservoirs and further how the gas/water level moved along the infilling/withdrawing annual cycle.

The common research programs ran over thirty years at different gas storages in the Paris Basin (Fig. 1): Gournaysur-Aronde (1980-1982), Germigny-sous-Coulombs (19911992), Céré-la-Ronde (1993-2001) and Saint-Clair-sur-Epte (1999-2003).

\section{GOURNAY-SUR-ARONDE (1980-1982)}

High resolution seismic surveys were performed on the Gournay-sur-Aronde underground storage facility of $G D F$ Suez (Blondin and Mari, 1986) in order to obtain information about gas bubble boundaries within the reservoir. For that purpose, weight-drop surface seismic surveys were carried out between 1980 and 1982 on the anticline structure. The quality of the seismic data was sufficiently high to estimate the lateral extension of the gas bubble. This lateral extension was observed both from an amplitude anomaly of the reservoir seismic horizons and from time shift anomalies between lines recorded at different times, showing a gas bubble movement.

The structure is an anticline with two culminations (Fig. 2), situated in the Paris basin about $80 \mathrm{~km}$ north-east of Paris. It has a closure of $65 \mathrm{~m}$, located in the north-west, with an area of $27 \mathrm{~km}^{2}$ (length $12 \mathrm{~km}$, width $2 \mathrm{~km}$ ). The reservoir formation is situated at a depth of $730 \mathrm{~m}$ and has an average thickness of $45 \mathrm{~m}$. It consists of two Sequanian sandstone levels (R2 lower level and R1 upper level) separated by a shaly intermediate layer (M7). The total mean porosity of the sandstones is $20 \%$, and their average permeability 0.6 Darcy. The total storage capacity is estimated at 3 billion $\mathrm{m}^{3}$ of gas, referred to standard conditions.

The reservoir is overlain by a leakproof caprock $180 \mathrm{~m}$ thick, made of Kimmeridgian calcareous shale. Isobaths of the upper reservoir level are shown in Figure 2. The gas is withdrawn in winter and filled in summer. The expansion of the gas bubble is checked by pressure measurements of the reservoir aquifer in verification wells either by measurements of the depth of the water level (gas/water interface) or by periodic measurements of gas saturation by means of neutron logs. The check of the inflow shows a preferential migration of gas toward the south-eastern part of the anticline, where lines 3, 4 and 5 were recorded in April 1981 and January 1982. The gas migration toward the secondary culmination in the North West seems to be more difficult. In order to obtain

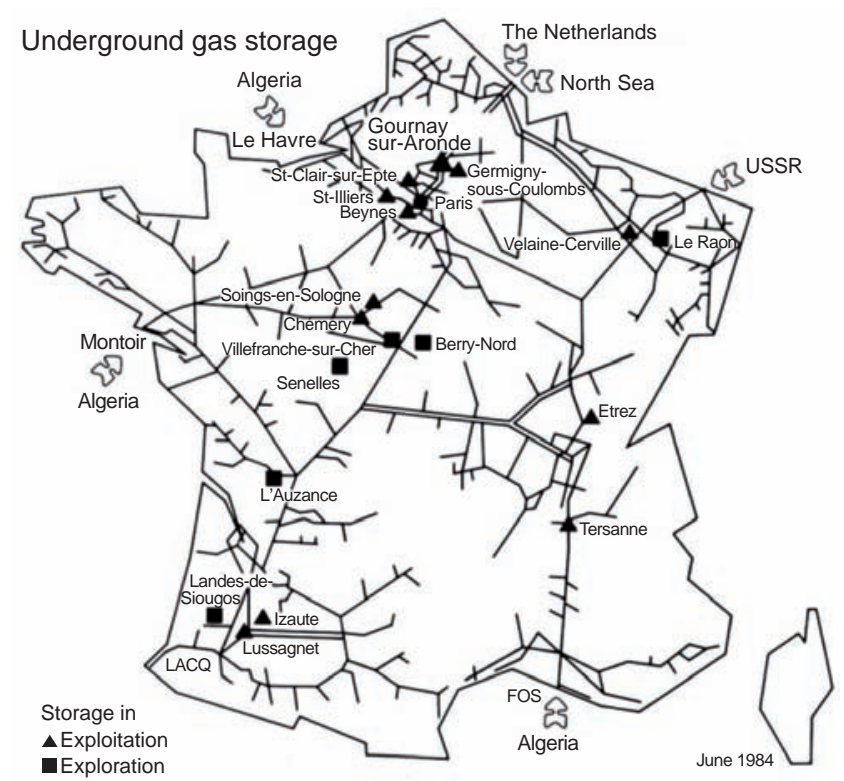

Figure 1

Underground gas storage location.

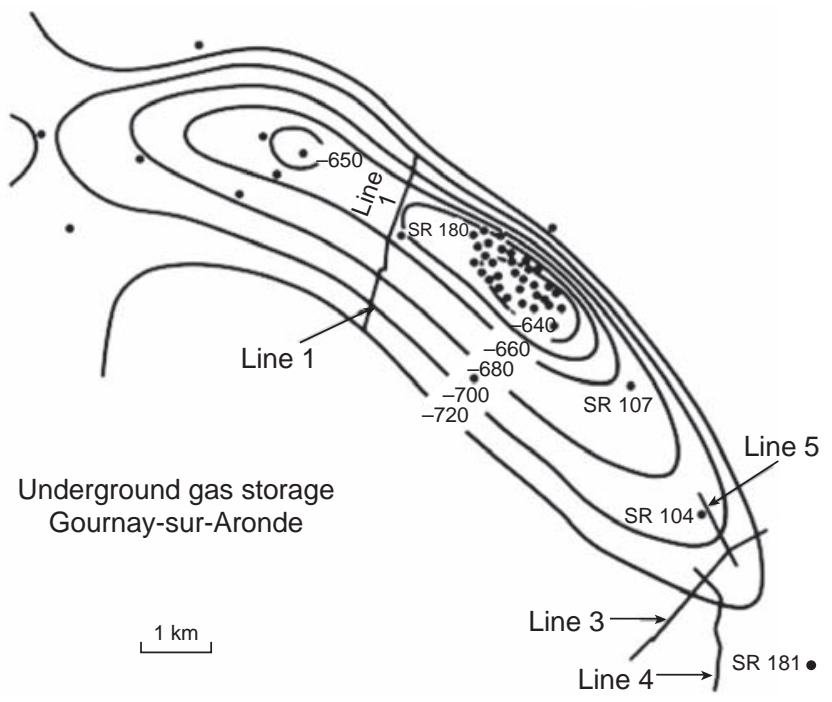

Figure 2

Position of seismic lines $1,3,4,5$ and locations of the wells. The solid lines show the isobaths of the upper reservoir level R1 (in meter, DP = sea level). 
Gournay-sur-Aronde gas storage gas bubble boundaries

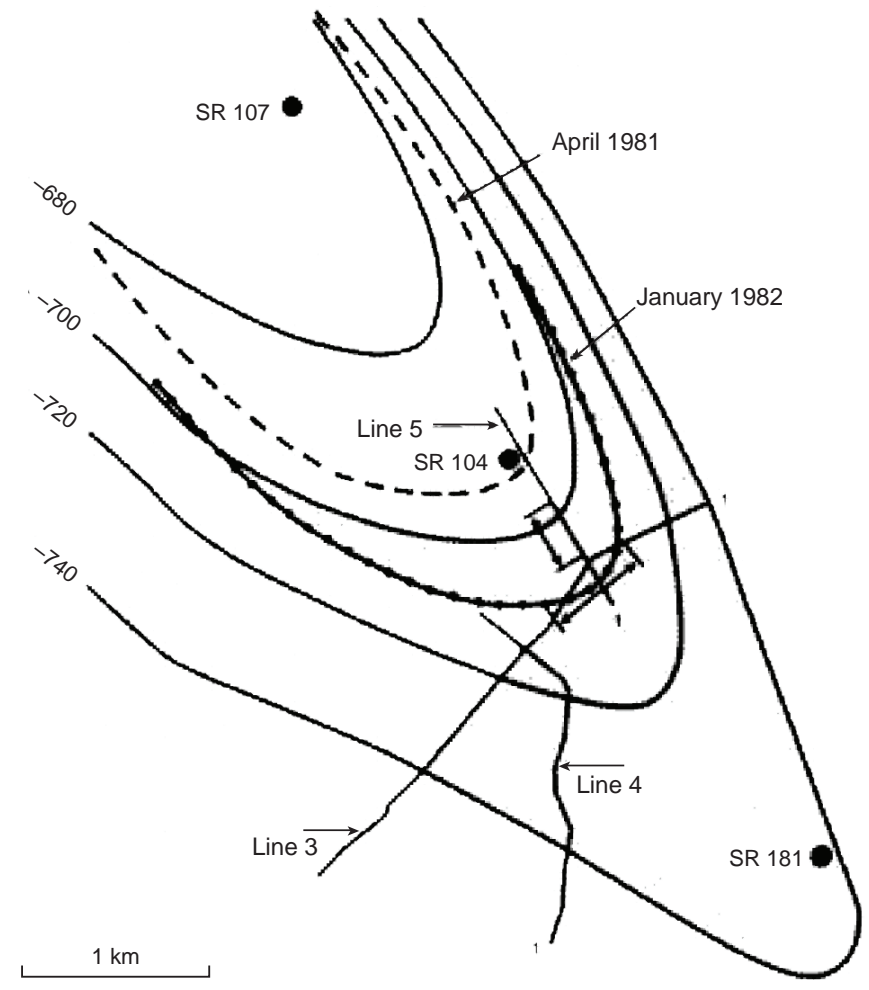

Figure 3
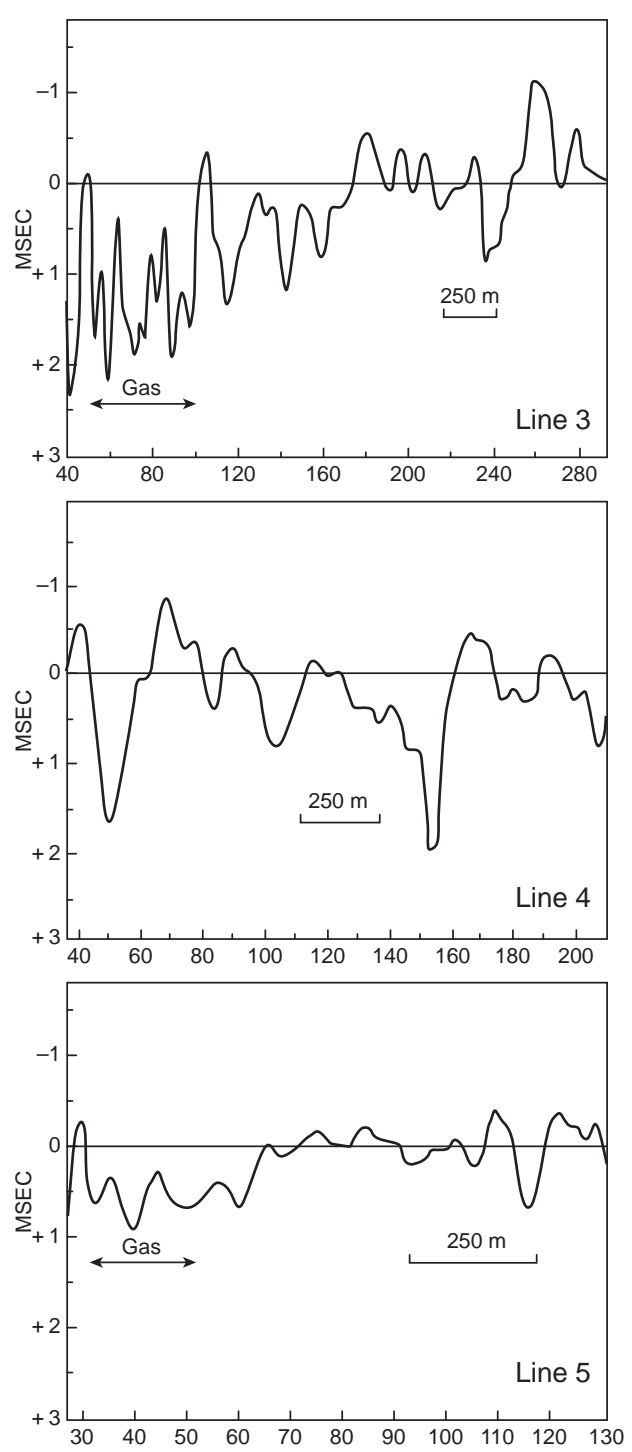

Monitoring gas movement at Gournay-sur-Aronde.

On the right: curves of residual time shifts observed below the reservoir from April 1981 to January 1982 on lines 3, 4 and 5.

On the left: topographic map showing the location of gas bubble boundaries in April 1981 and January 1982 (dotted lines) and of the position of the seismic lines. The arrows show the location of residual time-shift anomalies (described by the curves on the right) observed between the two surveys below the reservoir. The solid lines show the isobaths (in meter) of the upper reservoir level.

detailed information about this phenomenon, well SR 180 was drilled and line 1 was recorded in December 1982 on the northwest flank of the main culmination. Figure 2 shows the position of seismic lines 1, 3, 4 and 5 and the location of the wells.

The forward motion of the gas plume between April 1981 and January 82 was measured by an increase in the arrival time of reflections beneath the storage in the range of 0.5 to $1.5 \mathrm{~ms}$ (Fig. 3). In order to remove near-surface effects relative to variations of $P$-wave velocity in the first few meters, due to changes in temperature and humidity, the time shifts
$\Delta t$ were measured by the difference between correlation peaks of large time windows above $(\Delta t 1)$ and beneath $(\Delta t 2)$ the reservoirs.

Only variations with a width greater than the lateral resolution of reflection seismics, i.e., about a hundred meters, are taken into account. Wide events at the beginning of lines 3 and 5 are significant; variations in the right part of line 3 and variations in line 4, which does not intersect the gas plume, can be attributed to noise.

Such a range of time variation corresponds to a change in velocity of the order of $200-300 \mathrm{~m} / \mathrm{s}$. This experimental 


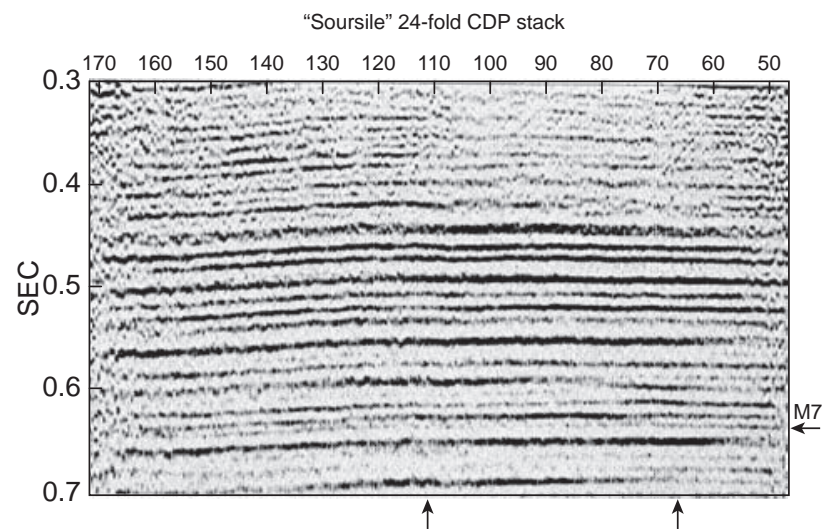

a)

Figure 4

Line 1 (see Fig. 2).

a) 24 fold CDP stack with $5 \mathrm{~m}$ CDP interval. At $0.63 \mathrm{~s}$, one can notice an amplitude decrease of seismic horizon M7. Extension of M7 amplitude decrease is shown by arrows.

b) Migrated time section. The amplitude anomaly of seismic marker M7 delimits the gas bubble boundaries.

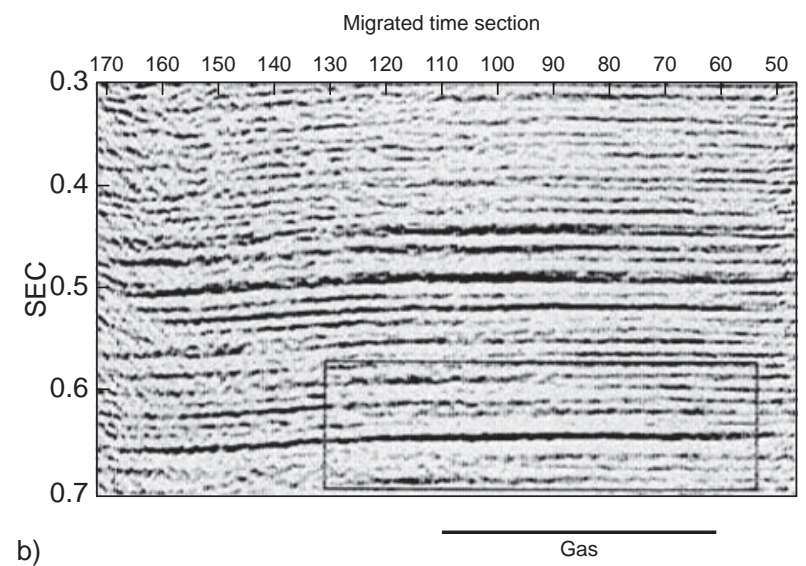

b) results are coherent with laboratory measurements (Toksöz et al., 1976).

The presence of gas could also be revealed by amplitude variations. The phenomenon has been observed on line 1 (Fig. 2).

Conventional processing was applied to the data, including editing, amplitude recovery, deconvolution, static and moveout corrections, residual static corrections, CDP stack and migration. Particular attention was paid to basic static corrections in order to preserve the high frequencies of the signal. A zero-phasing all pass filter was applied to the CDP stack in order to simplify the correlation between seismic section and well $\log$ data (sonic and density log recorded in well SR 180). Figure $4 \mathrm{a}$ shows the 24 fold CDP stack section obtained from line 1 . At $0.63 \mathrm{~s}$ between shot points 65 and 115 , one can notice an amplitude decrease of the seismic horizon M7 corresponding to the top of the lower reservoir layer (R2).

The zero-phase seismic section was then migrated in order to recover the dips and lateral amplitude variations of the seismic horizons and to put the M7 terminations nearer to their physical surface positions, allowing the amplitude anomaly extension to be mapped (Fig. 4b). We can see that at reservoir level reflection M7, which is present at both sides of the section, vanishes in the sector where gas is present.

The amplitude variation is, in this case, clearly visible, with the contrast between some amplitude and almost zero. This is a rather fortunate case, due to the presence of a shaly layer, M7, between the two sandstone levels (R1 and R2). When the storage reservoirs were filled with water, the acoustic impedance was smaller in the shale than in the sandstone. The presence of gas decreased the contrasts in acoustic impedance and, hence, the amplitude of the reflection. The phenomenon has been confirmed by computation of synthetic seismograms.

In many other cases, we do not have this chance and the amplitude differences are under the noise level.

\section{GERMIGNY-SOUS-COULOMBS (1991-1992)}

A permanent downhole system ( Laurent et al., 1999) including recording and transmission means and geophones, tied on the tubing, set down with it into the well and clamped to the casing by a spring, was designed, manufactured and tested at the GDF Suez. Germigny gas storage (Fig. 5).

The seismic response of the downhole geophones remained consistent during the two years of the experiment.

At Germigny, three geophones were set down, two above the reservoir and one below. The accuracy of the travel time between the two geophones on both sides of the reservoir was in the range of 0.05 millisecond, about ten times the accuracy of time measurements in surface seismic surveys (Deflandre et al., 1995).

\section{CÉRÉ-LA-RONDE (1993-2001)}

The gas reservoir at Céré-la-Ronde is located in the Loire Valley. Figure 6 shows the closure of the reservoir and the location of the faults. It also shows the location of the wells and of the seismic lines. It is a water-bearing sandstone formation in a faulted anticline structure. Two culminations were identified. On the central culmination, well CE12 was 


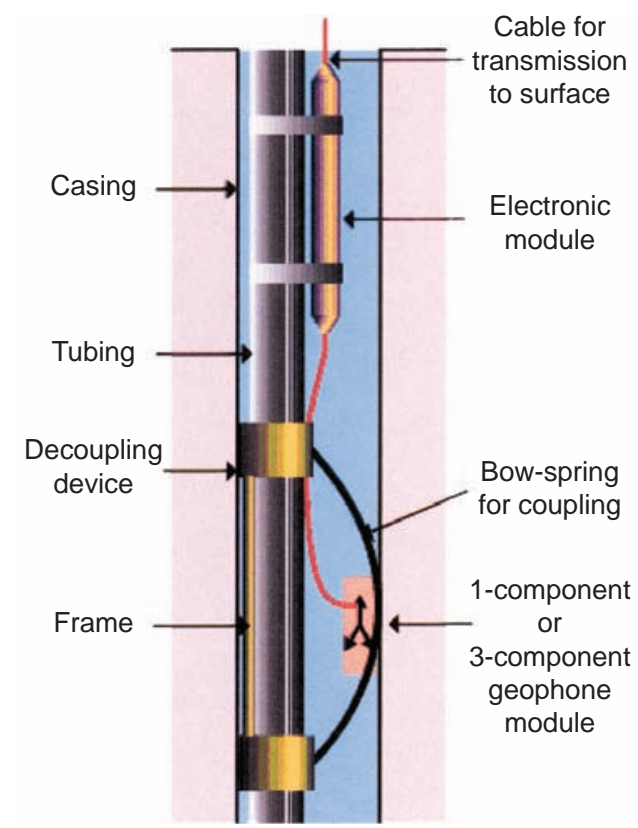

Figure 5

Permanent downhole geophone.

drilled, close to the injection well. This central structure, extending from north to south, is bordered by two faults. The main reservoir depth is $900 \mathrm{~m}$ and its average thickness is $70 \mathrm{~m}$, with maximum porosity in the interval $915-940 \mathrm{~m}$. The reservoir is covered either by a shaly cap rock or directly by a Hettangian shaly-dolomitic formation. The average porosity is $20 \%$, with a permeability of $3500 \mathrm{mD}$. In the interval 915-940 m, the porosity reaches $24 \%$. The first injection started in October 1993 and the first seismic acquisition was recorded in June 1993. This will be referred to below as the seismic reference.

The data recorded on the field site are: full wave form acoustic data, surface seismic data, well seismic data (walkaway VSP).

Four surface vibrator seismic surveys were recorded. Two seismic lines (M01 and M02) have been recorded at the same location as the walk away lines in order to increase the lateral investigation. Careful processing was applied to obtain a high quality section in the optimum frequency bandwidth 20-85 Hz.

Figure 7 shows the difference between seismic line M01 recorded in June 1993 (seismic reference, prior to gas injection) and the same line recorded in November 1994 (Meunier et al., 1998). The differential section shows amplitude variations at the level of the reservoir and beneath. The figure also shows colour-coded time shift anomalies below the zone where the gas has been injected. Beneath the reservoir, the amplitudes displayed in the differential section are related to the difference in arrival time of the reflections. Amplitude variations are also visible somewhat above the reservoir. This could be related to seismic effects of pressure variations.
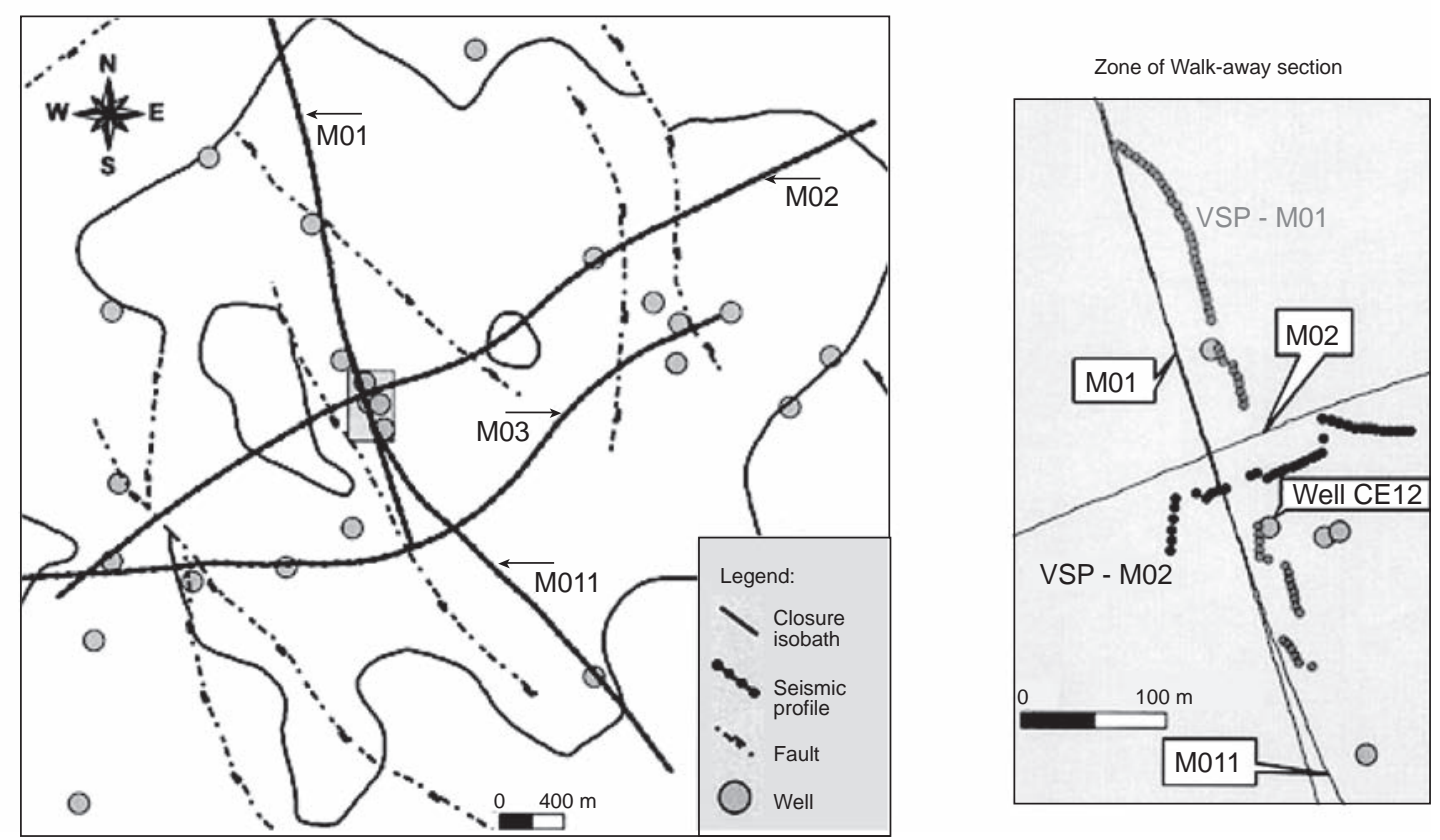

Figure 6

Céré-la-Ronde base map: surface seismic sections, walkaway sections, wells and closure isobath. 


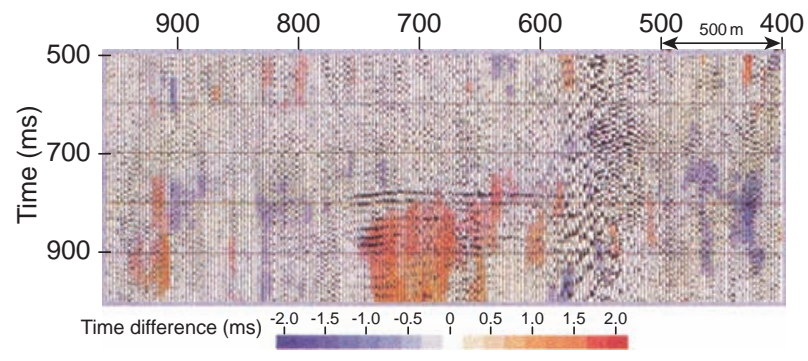

Figure 7

Differential section between seismic line M01 recorded in June 1993 (seismic reference, prior to gas injection) and the same line recorded in November 1994. The residual time shifts are colour-coded and superimposed to the differential section. The projection of the injection well on the seismic line is close to CDP 700 .

Laboratory measurements (Rasolofosaon and Zinszner, 2003) have shown that the $\mathrm{P}$ and $\mathrm{S}$-wave propagation velocities are sensitive to the effective stresses, i.e., to the difference between stresses in the medium and pore pressure, as was stated by Mindlin in 1949 for a model made of spheroidal balls.

The influence of the changes in pore pressure, related to gas injection or withdrawal, on the velocities and hence on the time shifts was found nearly equivalent to the influence of the fluid content, in the case of Céré-la-Ronde, particularly when looking to far offset amplitudes (Fig. 8). Stress variations can expend outside the reservoir, so that velocity variations can occur also at some distance of the reservoir (Vidal et al., 2002).

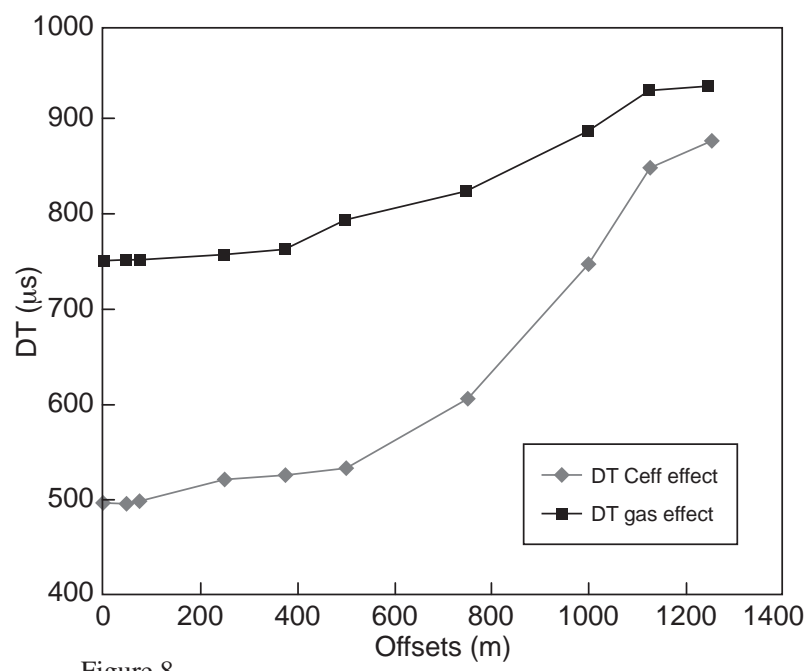

Figure 8

Time shifts $v s$ source-receiver offset. Time shift due to pore pressure and time shift due to gas injection are equivalent at large offsets.
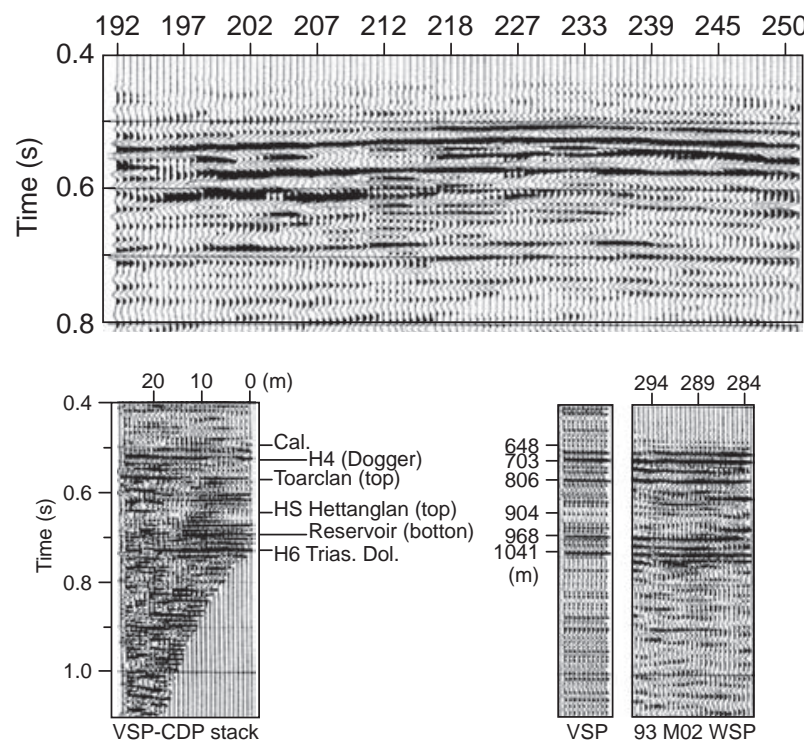

Figure 9

Example of VSP section (after processing) M01 line and correlation between the well sections and lithology.

\subsection{Permanent Downhole Geophones}

Two lines of walk away VSP have been recorded (Mari et al., 2000; Dumont et al., 2001). Line VSP-M01, orientated north-south, consists of 103 vibrating points with a maximum offset to the source of $800 \mathrm{~m}$. Line VSP-M02, orientated east-west, consists of 60 vibrator points and the maximum offset to the source is $500 \mathrm{~m}$. The vibrators performed sweeps in the $16-120 \mathrm{~Hz}$ frequency interval. The walk away lines extension is around $300-400 \mathrm{~m}$. The receiver array is in well CE 12. It comprises a spread of 15 downhole permanent geophones (Perseids) anchored over the depth interval 540-680 $\mathrm{m}$. The geophones are $10 \mathrm{~m}$ apart.

Figure 9 represents the VSP-M01 section used as a reference. It shows the anticline structure. Figure 9 also shows the correlation between the well sections (section from a conventional VSP recorded in well CE12, stacked trace of the VSP and the well seismic line VSP-M02) and the lithological information (identification of seismic horizon with depth).

With such a permanent recording system, measurement of time shifts with a precision of 0.1 to 0.2 millisecond was made possible between two time-lapse well seismic surveys.

The full lines (Fig. 10) display the time differences between surveys acquired in February 1994 and the reference acquired in June 1993. The dotted lines display the difference between the second monitor survey acquired in April 1994 and the reference. The two surveys were acquired during the initial filling period. The time shifts measured between two surveys are of the order of half a millisecond.

These time shifts, carefully measured by correlating windows above and beneath the reservoirs were utilized to 

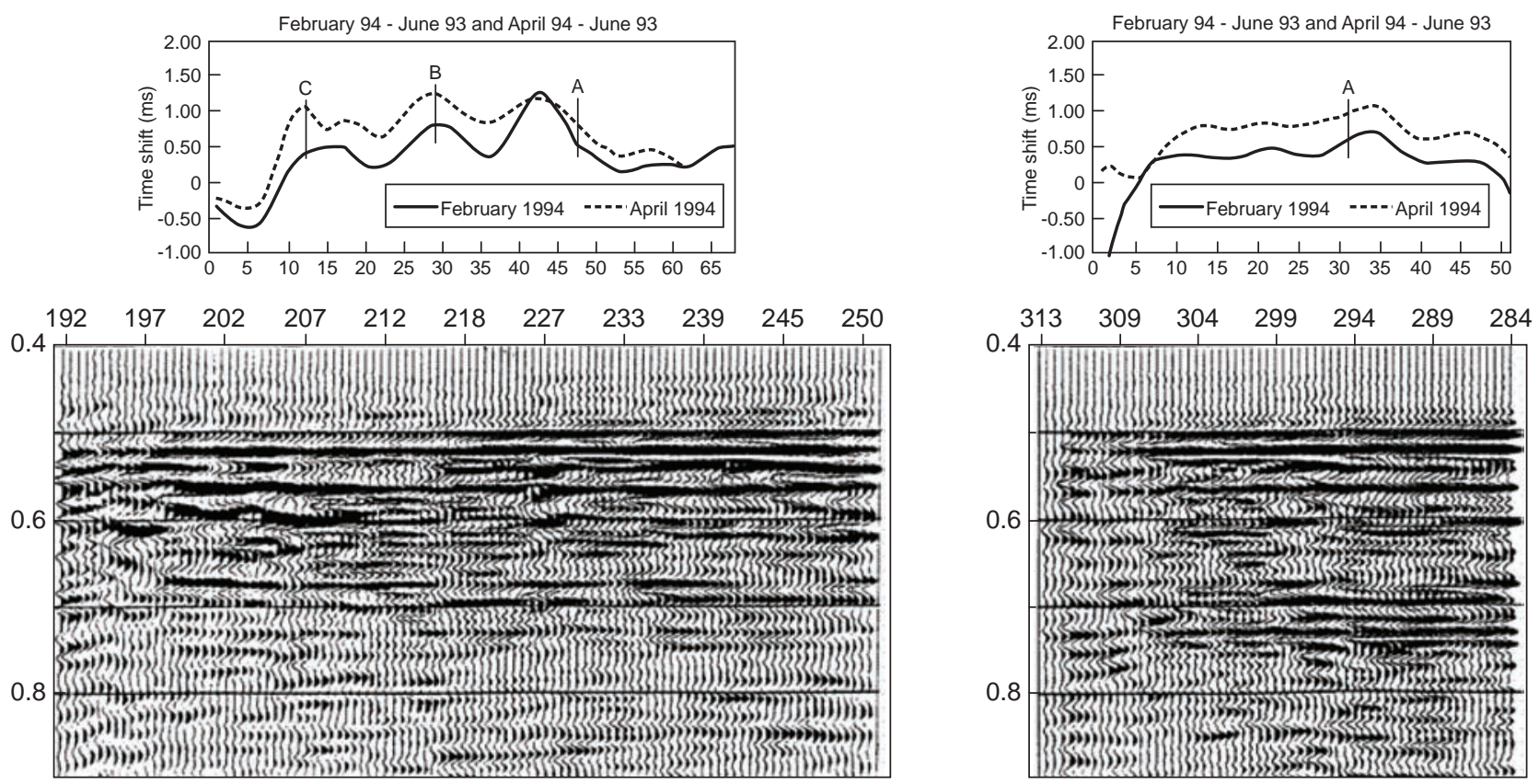

Figure 10

Walk away sections and time shifts.

estimate the porosities and the gas saturation along the walk away profiles (Mari et al., 2000; Dumont et al., 2001).

The ratio of the $P$-wave velocity in the reservoir at monitor time, when the reservoir is filled with water and gas, to the $P$-wave velocity at reference time, when the pores are entirely filled with water, is inversely proportional to the ratio of the travel times through the reservoir at these two periods, travel times that can be measured.

The $P$-wave propagation velocity in the reservoir can be computed, using Gassmann's relation, as a function of the mechanical characteristics of the rock, of the porosity and of the gas saturation.

The square of the velocity ratio (gas saturated over water saturated), named here saturation index, designed by $R_{x}$, and computed by making the ratio of the measured travel times through the reservoir with and without gas:

$$
R_{x}=\left(\frac{V_{P}^{g}}{V_{P}^{w}}\right)^{2}=\left(\frac{H_{t}}{H_{t}+\Delta t}\right)^{2}
$$

is displayed in the bottom left graph as a function of porosity for different gas saturations (Fig. 11).

Assuming that gas time thickness is only dependent on time shift measurement, the gas thickness $H t(x)$ can be computed from a specific function $S S(x, t)$ built as follows:

$$
S S(x, t)=\left[S R(x, t)-S I\left(x, t-\Delta t_{1}\right)\right] \cdot\left[S R(x, t)-S I\left(x, t-\Delta t_{2}\right)\right]
$$

where $S R(x, t)$ and $S I(x, t)$ are the reference (pre-injection) and the repeated seismic traces at CDP position $x, S I\left(x, t-\Delta t_{1}\right)$ and $S I\left(x, t-\Delta t_{2}\right)$ are the repeated seismic trace shifted by time delays computed by correlation with the reference trace in large time windows above and beneath the reservoir.

The specific function is the product of two terms. Each term is the subtraction of the $S R$ reference trace and the time

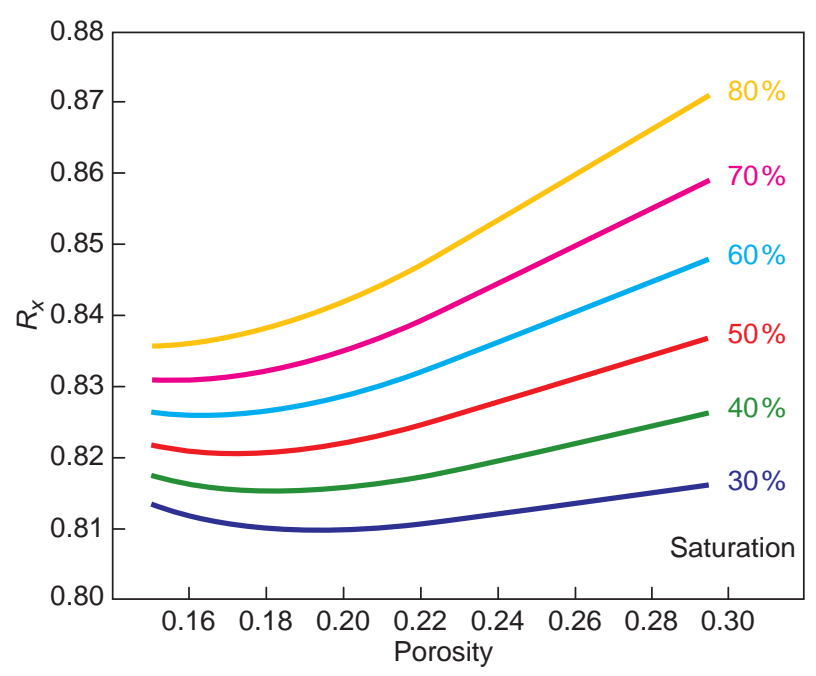

Figure 11

Saturation index $v s$ porosity for various gas saturations. 

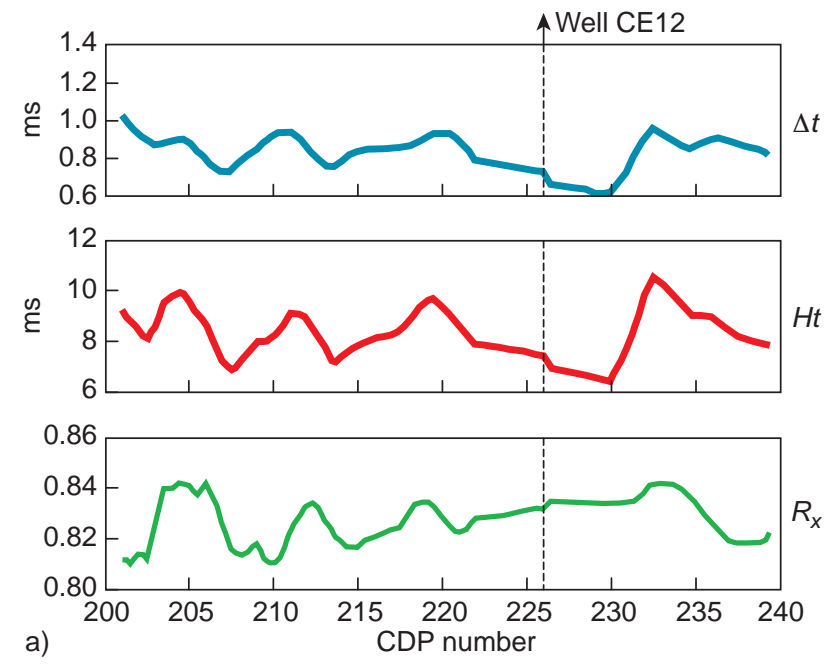

Figure 12

a) $\Delta t, H t$, and $R_{x}$ curves computed from VSP profile M01 between June 1993 and November 1995. b) Estimation of porosity and gas saturation with associated error ranges.

shifted SI repeated trace (after injection). The product of these 2 terms shows an anomaly with two extremes representing the top and the base of the reservoir which is partly gas saturated. So the distance between the two picks can be estimated as $H t$ the gas time thickness.

Figure 12 (on the left) shows from top to bottom the residual time shift curve $\Delta t=\Delta t_{2}-\Delta t_{1}$, difference between the two time delays obtained by correlation with the reference trace beneath and above the reservoir, the time gas thickness curve $H t$ and the gas saturation index $R_{x}$ along the VSP profile M01 between June 1993 and November 1995. Figure 12b shows the range of porosity-saturation couples which fit the $R_{x}$ curve shown in Figure 12a.

In the vicinity of well CE12, near CDP number 227, the mean porosity is equal to $23 \%$ and the mean saturation is estimated at $68 \%$. The results obtained are in good agreement with those given by time lapse sonic data.

\subsection{Permanent Sources}

The first years of the new century saw the development of permanent sources, which, combined to permanent receivers, allowed permanent recording.

The Seismovie system (Fig. 13) was initially composed of a light piezoelectric source, placed in a cave or cemented in a shallow well and permanent arrays of geophones and hydrophones cemented in wells of some hundreds of meters.

The Seismovie source vibrates with single frequencies, so that simultaneous emissions from several sources can be separated at processing stage and listening at natural noises in the reservoir is simultaneously possible (Meunier et al., 2001).
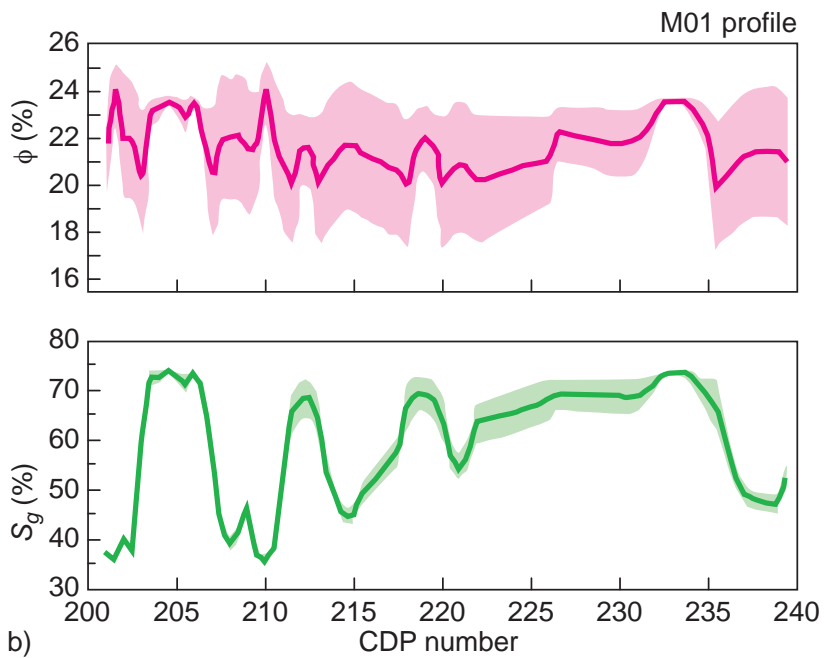

b)

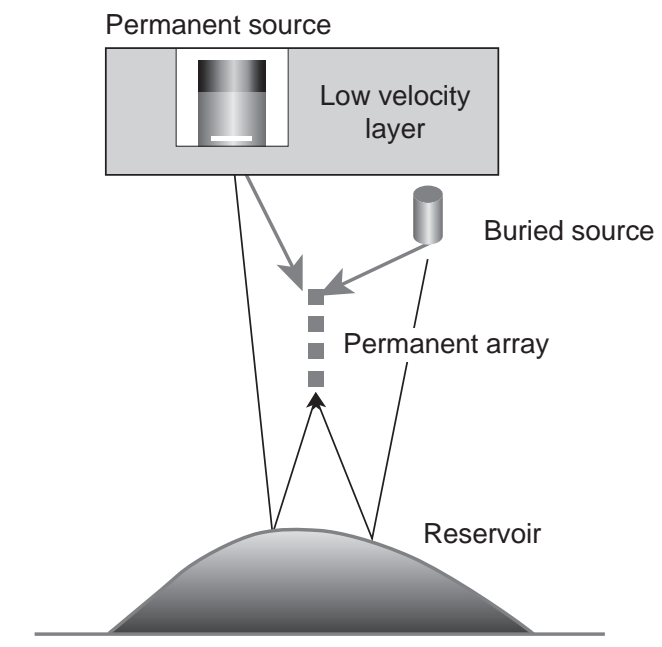

Figure 13

Permanent sources and receivers.

All the frequencies in the desired range are vibrated with a half-Hertz sampling and the time signal is reconstructed by a Fourier transform.

An experiment was carried out at the Céré-la-Ronde gas storage with a piezoelectric vibrator, bolted to a concrete pad at the surface. An array of 20 vertical geophones and hydrophones was set down and cemented between 80 and $175 \mathrm{~m}$ in a well just beneath the source.

Frequencies were vibrated during 16 seconds with a halfHertz sampling from 20 to $150 \mathrm{~Hz}$. The complete bandwidth was vibrated in one hour and half, so that about 15 "shots" could be obtained each day. 
The reconstructed time data recorded by each geophone and hydrophone were processed as Vertical Seismic Profile (VSP) data: The up- and down-going fields were separated by apparent velocity filtering and the up-going field was deconvolved by the down-going field. This process focuses the reflections and brings a correction for weather-related velocity variations in the first few meters below the surface, which impact in the same manner the up and down-going fields. The records of each receiver of the vertical array were shifted to the double reflection time by adding the downgoing travel time from surface to the receiver. These records were then summed together, giving birth to a single trace per shot.

These traces may be displayed one beside the other in a time-lapse section with the recording time (in milliseconds) in ordinate and the calendar time (in days, weeks and months) in abscissa. Figure 14 displays the differences of each trace with a reference trace, chosen at a time when the gas level was at a minimum, in March 2001. Differences are maximal in summer, when the gas level was at a maximum, and are relatively small between similar periods (March 2000-March 2001).

The differences are small over all the year far above the reservoirs, indicating that weathering variations have been corrected, but some variations are visible a little above, due to stress effects.

Time shifts can be measured by correlating the traces obtained by VSP processing for each record with a reference

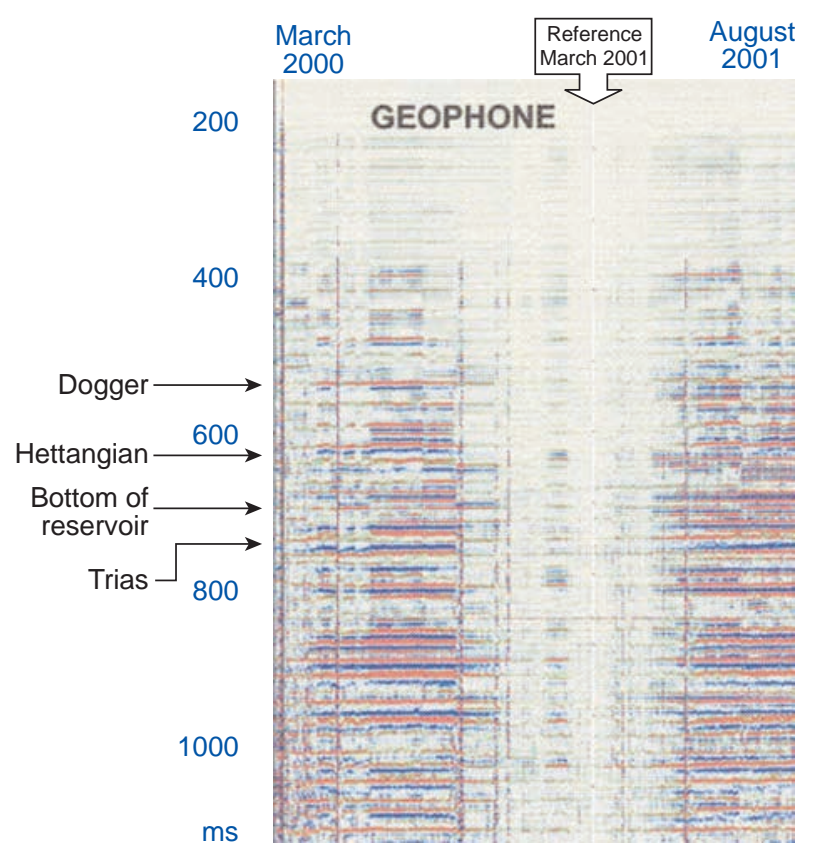

Figure 14

Seismovie time lapse difference sections.

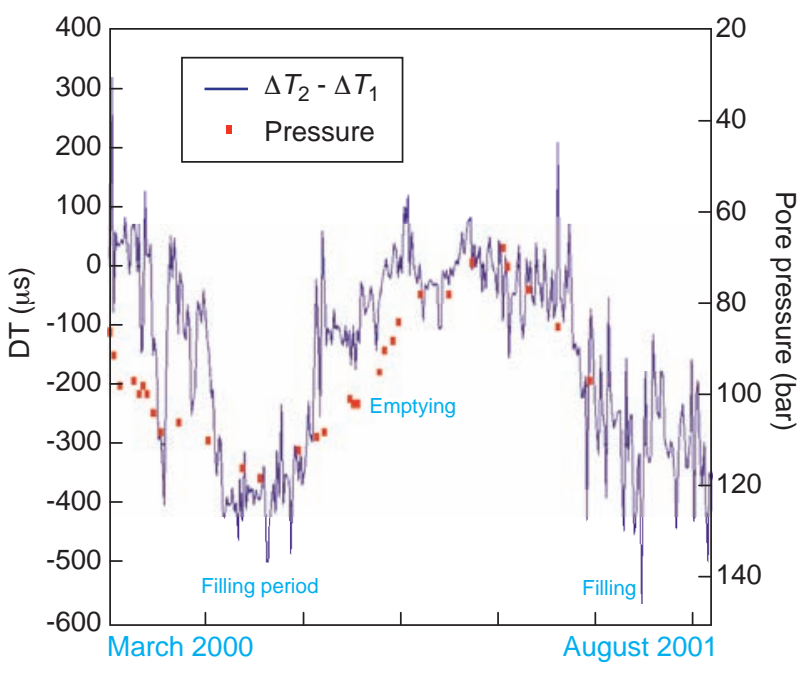

Figure 15

Time shifts and pressure variation from March 2000 to August 2001.

trace taken at a given time in large windows above and below the reservoirs. The difference between these time shifts, $\Delta T_{2}-\Delta T_{1}$, is supposed to give the difference in double travel time through the reservoir. Figure 15 displays this time shift difference over a whole year (Becquey et al., 2007). The reference time was taken at a time of low gas level in March. The downhole pressure was superimposed on the time shift curve. The pore pressure is displayed downward and the scales are chosen to bring out the correlation between these two measurements.

The two curves are broadly similar. The time shifts variations are, however, less regular than the pressure variations. They are relatively stable at medium to high pore pressure, but vary rapidly when the pore pressure is at a minimum, i.e., for weak gas saturation.

\section{SAINT-CLAIR-SUR-EPTE (2002-2004)}

An experiment with five simultaneous permanent sources was carried out at the GDF Suez natural gas storage in SaintClair-sur-Epte (Fig. 16).

Sources were placed at the corners, in shallow cemented caves and in the centre of a $500 \mathrm{~m}$ side square and vertical arrays were cemented in wells beneath each source, between 100 and 200 meters. The central source was cemented in a shallow well at a depth of 20 meters.

VSP processing was applied to the reconstructed data: deconvolution by the down-going field, time delay correction at the two-way time and summation of the data recorded at different levels, giving one trace per shot. All the traces 


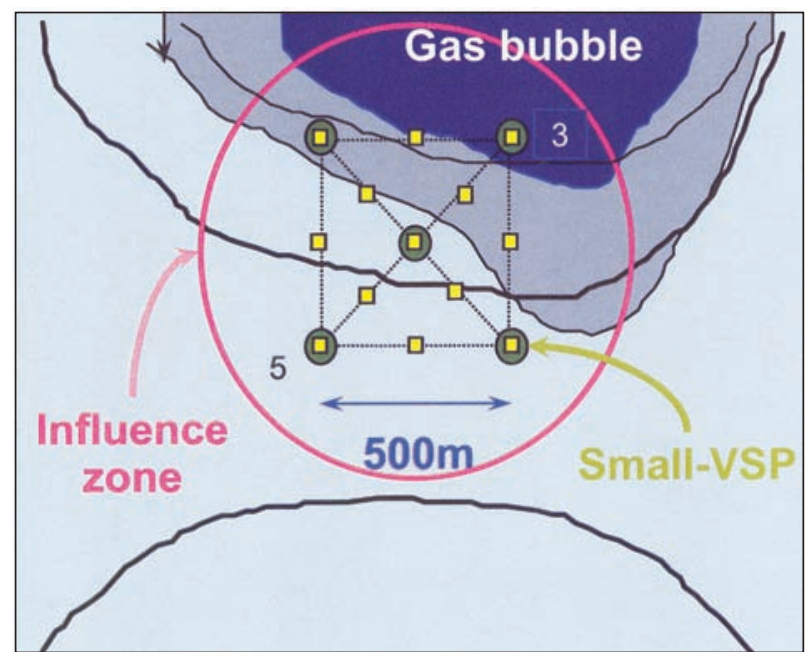

Figure 16

Saint-Clair Seismovie pattern.

acquired over a week were then stacked together, as significant changes were not expected in the reservoir during this lapse of time. Figure 17a are displayed time lapse sections, from December 2002 to July 2003, where each trace represents the records of a week.

Different markers were picked and the results are reported on the left for the sources at the north-eastern and southwestern corner of the pattern. Pickings on markers at 448 and $510 \mathrm{~ms}$, above the reservoir zone, at $540 \mathrm{~ms}$, at the level of the upper reservoir, and at $700 \mathrm{~ms}$, below the reservoirs, are represented one upon the other around a reference line. The grey band on each side of the reference line has a width of 2 milliseconds. Seismic markers well above the reservoirs are relatively flat all along the year, with differences less than $0.2 \mathrm{~ms}$, while markers in the reservoir zone (in yellow) and below (in light blue) show an increase in arrival time during the filling period, up to about 1.4 millisecond.

The data recorded by the two other corner sources were too noisy to be interpreted.

Because of electrical problems encountered with the central array, a new shallow well was drilled in 2003 in the centre of the pattern and a new array was set down. Figure $17 \mathrm{~b}$ shows the time shifts from November 2003 to July 2004 for this new array. Trace summations include all the records during fifteen days. Correlations have been performed with a reference trace in different windows. The bands on each side of the reference line have a width of one millisecond. The curves confirm the measures made the year before with the sources and arrays at the corners of the pattern: horizons far above the reservoirs are flat within an error of less than $0.2 \mathrm{~ms}$. Windows beneath the reservoir show an annual variation of about $1.4 \mathrm{~ms}$, with a minimum in March and April, when the gas level is low and a maximum in summer, when it is high. The variations begin above the reservoirs due to pressure variations.

Since the test period reported here, Seismovie has gained technical improvements, wider applications, as the use of areal receiving patterns. The precision of the arrival time
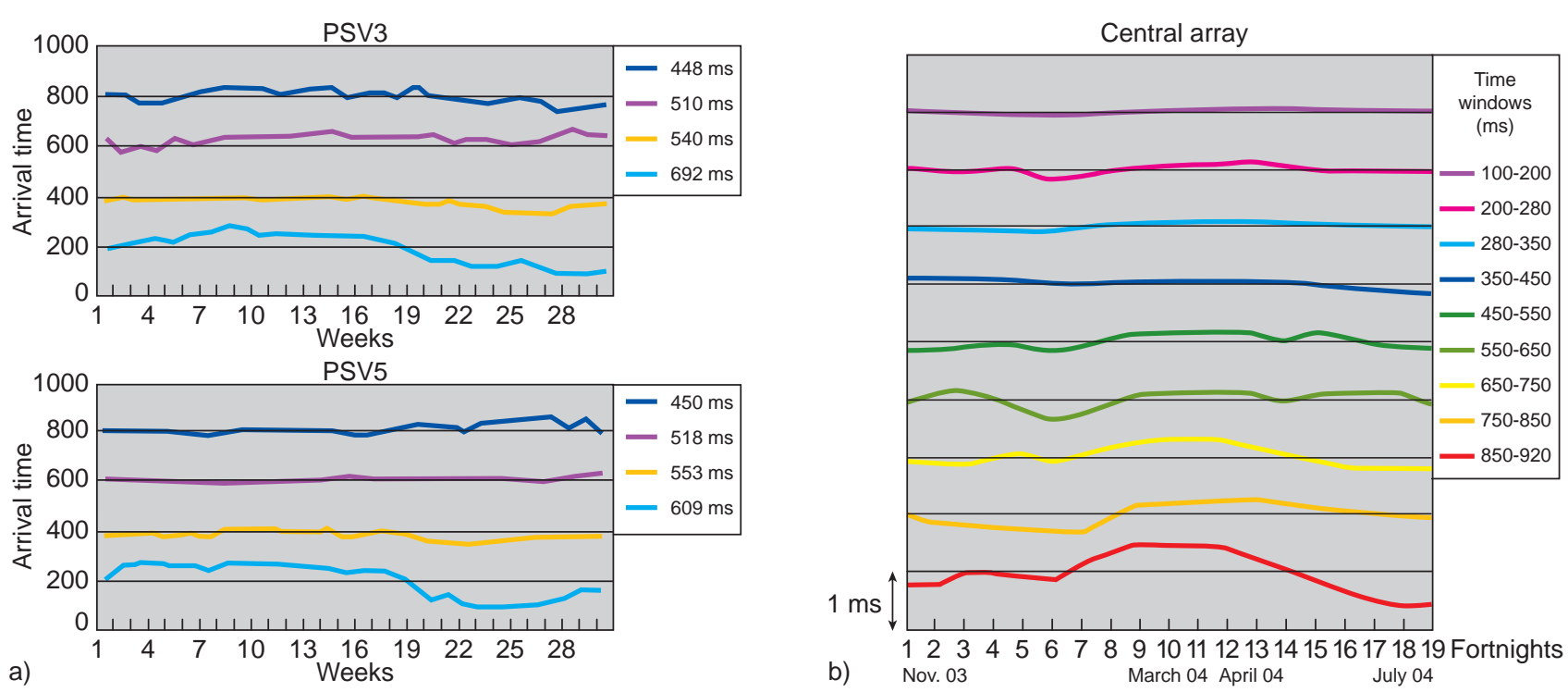

Figure 17

a) Picked horizon time shifts for the north eastern and the south western sources and arrays. b) Correlation with a reference trace in various time windows - Central source and array. 
measurements was estimated at less than $10 \mu$ s for a buried source and buried receivers (Schissele et al., 2009).

\section{FROM METHANE TO CARBON DIOXIDE}

Substitution and stress effects, time shifts and amplitude differences between two time lapse surveys can be detected by seismic methods for natural gas storage, owing to the fact that the arrival of a small quantity of gas in pores occupied by liquid decreases dramatically the $P$-wave propagation velocity.

When the gas saturation increases, however, the velocity variation is smoother. Beyond a gas saturation of 5 to $10 \%$, the velocity increase slowly and almost linearly with the gas saturation. An estimation of this linear dependence can be obtained by a Taylor expansion of Gassmann's relation for low water saturation, giving:

$$
V_{P} \approx \frac{K_{d r y}}{\rho_{d r y}}\left(1-\frac{\Delta \rho_{\text {fluid }}}{2 \rho_{d r y}} \phi S_{w}\right)
$$

where $K_{d r y}$ and $\rho_{d r y}$ are the bulk modulus and the density of the dry rock, $\Delta \rho_{\text {fluid }}=\rho_{\text {brine }}-\rho_{\text {gas }}$ is the density difference between the two fluids filling the pores, $\phi$ the porosity and $S_{w}$ the water saturation (Whitman and Towle, 1992).

Attempts have been made to estimate quantitatively the porosities and saturations in the weak slope part of the curve, with some results in the case of Céré-la-Ronde reported above.

What might be possible with difficulty for natural gas might be more difficult for $\mathrm{CO}_{2}$.

Taylor development of the Gassmann relation shows that the slope of the squared velocity as function of water saturation is determined by the fluid density difference. The density of carbon dioxide in a supercritical phase is about 0.6 to $0.7 \mathrm{~g} / \mathrm{cm}^{3}$ for a reservoir at a depth between 800 and $2000 \mathrm{~m}$. The density difference between $\mathrm{CO}_{2}$ and brine will be about half the difference value for methane, so that estimating the saturations will be still more difficult for $\mathrm{CO}_{2}$ storage monitoring (Becquey et al., 2007).

\section{CONCLUSIONS}

A series of seismic monitoring experiments were conducted by IFP Energies nouvelles, CGGVeritas and GDF Suez in order to detect and follow the movements of the gas plume in natural deep aquifers. Gas intrusion into an aquifer leads to an increase in the arrival times of reflections beneath the storage reservoirs, with a delay of about one millisecond, and to a variation of the reflection amplitudes in the reservoir zone that enables a delimitation of the zones containing some gas with an accuracy of a few tens of meters. Changes in the effective stresses also contribute to reflection travel time variations.
The geophysical parameters measured during the monitoring experiments are time shift and amplitude variations observed on seismic horizons versus calendar time. The more sensitive one is the time shift. Several seismic survey designs have been used:

- conventional surface seismic acquisition (Gournay-surAronde, Céré-la-Ronde);

- well seismic acquisition with permanent down-hole geophones (Germigny-sous-Coulombs, Céré-la-Ronde);

- well seismic acquisition with permanent down-hole geophones and permanent sources (Saint-Clair-sur-Epte).

Permanent source and receivers arrays, providing time measurement accuracy within a tenth of a millisecond, were designed and experimented in the field. The infilling/pumping out cycles were followed during pluriannual experiments. Progressive variations of the seismic parameters may be followed during the initial infill period. Further movements of the gas plume with the annual in/out cycles are more difficult to follow, because of the simultaneous presence of gas and water in the rock pores. Arrival time variations of some tenths of a millisecond may be detected and measured. Saturations, using accurate picking of the arrival times, can be estimated in favourable cases.

The methodology developed for monitoring methane injection in aquifer reservoir could be implemented for monitoring $\mathrm{CO}_{2}$ injection in deep aquifer. However, because of the higher density of carbon dioxide, when stored in a supercritical phase, sensitivity of the seismic parameters, velocity, density and acoustic impedance to saturation variations will be about twice smaller for $\mathrm{CO}_{2}$ storages than it is for methane, monitoring of $\mathrm{CO}_{2}$ injection by seismic methods with permanent source and receivers arrays will be difficult and will required data with a good signal to noise ratio.

\section{ACKNOWLEDGMENTS}

Most of the research projects carried out by GDF Suez, CGGVeritas and IFP Energies nouvelles about underground storage monitoring were supported by the French Exploration and Production Programme Committee.

\section{REFERENCES}

Toksöz M.N., Cheng C.H., Timur A. (1976) Velocities if seismic waves in porous rocks, Geophysics 41, 621-645.

Blondin E., Mari J.L. (1986) Detection of gas bubble boundary movement, Geophys. Prospect. 34, 73-93.

Whitman W.W., Towle G.H. (1992) The influence of elastic and density properties on the behavior of the Gassmann relation, The Log Analyst, Nov.-Dec. 92, 500-506. 
Deflandre J.P., Laurent J., Michon D., Blondin E. (1995) Microseismic surveying and repeated VSPs for monitoring an underground gas storage reservoir using permanent geophones, First Break 13, 129-138.

Meunier J., Huguet F. (1998) Céré-la-Ronde: A laboratory for timelapse monitoring in the Paris Basin, The Leading Edge 17, 1388-1394.

Laurent J., Deflandre J.P., Dubois J.C., Huguet F. (1999) Permanent Downhole Geophones: an efficient approach for reservoir monitoring, Eurogas 99.

Mari J.L., Fayemendy C., Dumont M.H., Huguet F. (2000) Saturation Estimation Using Both Seismic and Well Data, EAGESAID Conference "Petrophysics meets Geophysics", abstracts A06.

Dumont M.H., Fayemendy C., Mari J.L., Huguet F. (2001) Underground gas storage: estimating gas column height and saturation with time lapse seismic, Petrol. Geosci. 7, 155-162.

Meunier J., Huguet F., Meynier P. (2001) Reservoir monitoring using permanent sources and vertical receiver antennae: The Céré-laRonde case study, The Leading Edge 20, 622-629.
Vidal S., Huguet F., Mechler P. (2002) Characterizing reservoir parameters by integrating seismic monitoring and geomechanics, The Leading Edge 21, 295-301.

Rasolofosaon P., Zinszner B. (2003) Characterization of reservoir rocks for seismic monitoring studies. Laboratory measurement of Hertz and Gassmann parameters, Oil Gas Sci. Technol. - Rev. IFP 58, 615-635.

Becquey M., Bruneau J., Huguet F., Meunier J., Rasolofosaon P., Vidal-Gilbert S., Dietrich M. (2007) Methane and $\mathrm{CO}_{2}$ : Can we estimate stored volumes by seismic measurements? GeoTechnologien Sci.Report 9, 8-12.

Schissele E., Forgues E., Echappé J., Meunier J., de Pellegars O., Hubans C. (2009) Seismic Repeatability - Is There a Limit? 71st EAGE Conference, V021.

Final manuscript received in November 2009 Published online in February 2011 